\title{
Prevalence of selected mental disorders among graduation class adolescents: data from a screening study
}

\author{
KATARZYNA NOWICKA-SAUER ${ }^{1, A, D-F}$, BARTOSZ KARCZ2, A, B, C, E, \\ ALEKSANDRA DYMOWSKA ${ }^{3,4, B, D, F}$, JANUSZ SIEBERT $^{1, \mathrm{E}}$ \\ ${ }^{1}$ Department of Family Medicine, Medical University of Gdansk, Poland \\ ${ }^{2}$ Institute of Human Development, SWPS - University of Social Sciences and Humanities, Sopot, Poland \\ ${ }^{3}$ Institute of Social Pathology and Rehabilitation, University of Gdansk, Poland \\ ${ }^{4}$ Center for Prevention and Addiction Therapy, Gdynia, Poland
}

A - Study Design, B - Data Collection, C - Statistical Analysis, D - Data Interpretation, E - Manuscript Preparation, F - Literature Search, G - Funds Collection

Summary Background. An increase in the prevalence of mental disorders and suicidal attempts is being observed worldwide. This tendency is also being noted among adolescents. A consistent screening for mental disorders among adolescents can be helpful in early diagnosis.

Objectives. The aim of the study was to assess the prevalence of selected mental disorders among graduation class adolescents by means of a screening assessment.

Material and methods. The study sample consisted of 399 graduation class adolescents, including 221 (55.4\%) women and 178 (44.6\%) men. The median age was 18.0 years. The Primary Care Evaluation of Mental Disorders Patient Health Questionnaire (PRIME-MD PHQ) was used.

Results. 'Alcohol abuse' was preliminary diagnosed in 134 (33.6\%) participants and was the most common disorder in the studied group. A preliminary diagnosis of 'major depression' was made in $21(6.2 \%)$ adolescents. The same prevalence $-60(15 \%)-$ of 'other depressive' and 'other anxiety disorders' was noted. In 10 participants (2.5\%), 'panic syndrome' was preliminary diagnosed. Bulimia nervosa was suspected in $5(1.3 \%)$ of the participants, and 'other eating disorders' in 34 (8.5\%). 'Other depressive disorders' and 'other anxiety disorders' were more common in women than men ( $p=0.002$ and $p=0.029$, respectively). 'Alcohol abuse' was significantly more prevalent among men $(p=0.025)$.

Conclusions. 1. Preliminary diagnosis of alcohol abuse was the most common in the studied adolescent group. This problem was especially frequent among men. 2. Psycho-educative intervention is of great importance among youngsters, especially among graduation adolescents. 3. Screening for mental disorders among graduation adolescents seems vital.

Key words: mental disorders, adolescent, public health.

Nowicka-Sauer K, Karcz B, Dymowska A, Siebert J. Prevalence of select mental disorders among graduation class adolescents: data from a screening study. Fam Med Prim Care Rev 2018; 20(3): 241-244, doi: https://doi.org/10.5114/fmpcr.2018.78259.

\section{Background}

Mental disorders include a wide range of problems with various symptoms involving a malfunction at the level of thoughts, emotions, behaviors and relationships with others. Examples of such disorders can be: anxiety disorders, depression, sleeping or eating disorders, substance abuse and addiction. There is a rapid increase in the incidence of mental disorders, both in Poland and other European countries [1-3].

According to data from EZOP (Epidemiologia zaburzeń psychicznych i dostępność psychiatrycznej opieki zdrowotnej EZOP - Polska) - a large Polish epidemiological study of a representative population sample of adults (aged 18-64) based on DSM-IV criteria - the most prevalent life-time mental disorders in Poland are alcohol abuse $(10.9 \%)$, panic attacks $(6.2 \%)$ and depression (3\%). In the 18-29 age group, the most prevalent are: alcohol abuse (13\%), panic disorder (2.9), specific phobia (2.9), substance abuse (2.3) and major depression (1.5\%) [2]. Polish studies have also shown that about $11 \%$ of adolescents overuse alcohol, $6 \%$ suffer from panic attacks, and $3 \%$ suffer from depression.

The Saving and Empowering Young Lives in Europe (SEYLE), a randomized controlled trial conducted in 10 European countries (168 schools, 11.110 pupils) aimed at assessment of health and risky behaviors, mental disorders and suicide among ado- lescents (age 14-16 years), revealed that $13.4 \%$ of adolescents drink alcohol 2-3 times per week. The prevalence of depression was $10.5 \%$, subthreshold depression $-32 \%$, while the rate of anxiety disorders was $5.8 \%$ and subthreshold anxiety $-29.2 \%$. These disorders were also significantly related to suicidal thoughts and behaviors [3].

Research also revealed that both adolescent girls and young women are at a higher risk of depression, anxiety disorders and suicidal thoughts, while alcohol use and abuse, as well as completed suicide rates, are significantly higher in adolescent boys and young men [2-4]. For example, according to data from the EZOP study published in 2015, lifetime depression is observed in $4 \%$ of women and $1.9 \%$ of men, panic attacks in $8.5 \%$ of women and $3.9 \%$ of men, and alcohol abuse in $18.6 \%$ of men and $3.3 \%$ of women [2].

The problem of mental disorders and suicidality among adolescents and young adults is significant, as a World Health Organization (WHO) report shows that suicide is the second most common cause of death among 15-29-year-olds [5], and this is proven to be related to depression and/or anxiety. A high rate of suicidal attempts among adolescents and young adults has also observed in Poland. In 2017, 5,276 persons (4,524 men and 751 women) committed suicide. Among them were 115 adolescents between 13-18 and 353 persons aged 19-24 [4]. 
One of the problems related to mental disorders in adolescents that emerged from a review of literature is the low rate of youngsters receiving appropriate care. Research has shown that only $50 \%$ of adolescents who suffer from severe impairment related to mental health problems is under specialist care [6].

It is emphasized that the first vital step in the treatment of mental disorders, as well as preventing suicide, is the identification of mental health problem, including subthreshold disorders, as well as risky behaviors $[6,7]$. Hence, improvement of identification of mental health problems at their early stage is of great importance $[7,8]$. Screening tests are helpful in identifying people at risk of mental disorders, as well as preliminary diagnosis of mental health problems, as well as the risk of suicide [3, 9]. Although one of the disadvantages of a screening test can be false positive results, it is emphasized that identification of subthreshold disorders is of great importance, since these may evolve into more severe disorders with comorbid psychiatric symptoms and increased suicidality [7].

As a review of literature revealed, the topic is very important, especially considering the developmental matriculation of high school graduates. There is no systematic assessment of the prevalence of mental disorders among high school graduates, and therefore a gap is formed for early diagnosis and directing accurate help for individuals at risk. It is suggested that a screening for mental disorders can and should be done by a primary care physician or school teachers $[3,9]$.

\section{Objectives}

The purpose of the present study was to assess the prevalence of select mental disorders among graduation class adolescents.

\section{Material and methods}

\section{Study design}

This is a report from a screening study.

\section{Setting}

The study was performed in the Pomerania region in Poland in cooperation with the high schools. The data was collected in 2016, and statistical analyses were made in 2017

\section{Participants}

The study involved 399 graduation class adolescents, including 221 women (55.4\%) and 178 (44.6\%) men. Inclusion criteria were: age 18 years and above and agreement for participation in the study. The median age of the participants was 18.0 years (range: 18-21 years). The responses were collected anonymously.

\section{Measures}

The Primary Care Evaluation of Mental Disorders Patient Health Questionnaire (PRIME-MD PHQ) was used to assess selected mental disorders. PRIME-MD PHQ is a standardized test developed for the purpose of preliminary diagnosis of five common types of mental disorders among primary care patients: somatoform disorders, depression (major depression, 'other depressive disorders', anxiety ('panic syndrome', 'other anxiety disorders'), alcohol abuse and eating disorders ('bulimia nervosa' and 'other eating disorders'). The method was created on the basis of Diagnostic and Statistical Manual of Mental Disorders IV th Edition (DSM-IV) criteria and is recommended to be used as a screening test for preliminary diagnosis of mental disorders. The preliminary diagnosis of a particular disorder de- mands the presence of a specific number and duration of symptoms according to DSM-IV criteria included in the coding system $[9,10]$. The assessment of somatoform disorders was excluded from the current analysis, since no objective data on medical health status was available. A request for information related to sex and age was included in the questionnaire.

The present study obtained the approval of the Independent Bioethics Commission for Research of Medical University in Gdańsk (permission number: NKBBN/190/2016).

\section{Statistical methods}

All statistical analyses were performed using SPSS 24 software. The Shapiro-Wilk test for normality was used. Categorical variables are presented as absolute values and percentage. Quantitative variable (age) is presented as median and minimum and maximum values. The chi-square test was performed to examine the significance of differences between sexes. A significance level of $p=0.05$ was used.

\section{Results}

A preliminary diagnosis of 'major depression' was observed in 21 adolescents (6.2\%), 14 women (7.9\%) and 7 men (4.3\%). 'Other depressive disorders' were preliminary diagnosed in $15 \%$ $(n=60)$, and this was significantly more frequent in women ( $n$ $=44 ; 19.9 \%)$ than men $(n=16 ; 9 \%)$. A preliminary diagnosis of 'other anxiety disorders' was made in $15 \%(n=60)$. This type of anxiety was more common among women $(n=41 ; 18.6 \%)$ compared to men $(19 ; 10.7 \%)$. In total, 134 youngsters (33.6\%) gave responses indicating a preliminary diagnosis of 'alcohol abuse'. This problem was more frequently presented by men $(n=70$; $39.3 \%)$ than by women $(n=64 ; 29 \%)$, with significant differences between sexes $(p=0.025)$. 'Panic syndrome' was preliminary diagnosed in 60 (15\%), 'bulimia nervosa' in $5(1.3 \%)$, and 'other eating disorders' in 34 (8.5\%). No between-sex differences were found for these problems. The results are presented in Table 1.

\begin{tabular}{|c|c|c|c|c|}
\hline $\begin{array}{l}\text { Mental } \\
\text { disorders* }\end{array}$ & $\begin{array}{l}\text { Study } \\
\text { sample } \\
n(\%)\end{array}$ & $\begin{array}{l}\text { Women } \\
n(\%)\end{array}$ & $\begin{array}{l}\text { Men } \\
n(\%)\end{array}$ & $p$ \\
\hline Major depression & $21(6.2)$ & $14(7.9)$ & $7(4.3)$ & 0.171 \\
\hline $\begin{array}{l}\text { Other depressive } \\
\text { disorders }\end{array}$ & $60(15)$ & 44 (19.9) & $16(9)$ & $0.002 * *$ \\
\hline Panic syndrome & $10(2.5)$ & $8(3.6)$ & $2(1.1)$ & 0.113 \\
\hline $\begin{array}{l}\text { Other anxiety } \\
\text { disorders }\end{array}$ & $60(15)$ & 41 (18.6) & $19(10.7)$ & $0.029 * *$ \\
\hline Alcohol abuse & $134(33.6)$ & $64(29)$ & $70(39.3)$ & $0.025^{* *}$ \\
\hline Bulimia nervosa & $5(1.3)$ & $3(1.4)$ & $2(1.1)$ & 0.855 \\
\hline $\begin{array}{l}\text { Other eating } \\
\text { disorders }\end{array}$ & $34(8.5)$ & $22(10)$ & $12(6.7)$ & 0.253 \\
\hline
\end{tabular}

* According to PRIME-MD PHQ and DSM-IV; ** statistically significant; $p<0.05$;

\section{Discussion}

The current study showed that a significant group of graduation class adolescents may suffer from various mental disorders. Taking into account the high risk of mental disorders and suicide rate in Poland $[4,11]$, the study seems to be of great importance. The noted prevalence of mental disorders was similar to those observed in previous studies $[3,12,13]$, including a randomized control study conducted among teenagers in 10 European countries (SEYLE study) [3]. The most prevalent disorder 
in the present study was alcohol abuse. The abovementioned SEYLE study revealed that about $13 \%$ of adolescents use alcohol [3]. Modrzejewska and Bomba [14] noted a high prevalence of alcohol use in Polish adolescents at age 17. It should be noted that the prevalence of alcohol abuse observed in our study $33.6 \%$ - was higher than in other authors' studies. This result can be partially explained by the use of a screening test according to which any positive answer reflecting the presence of any of 5 symptoms related to alcohol overuse justified the preliminary diagnosis of 'alcohol abuse'. One should keep in mind that a false positive result may occur, and we would recommend treating this result with caution. Additionally, in every case, a preliminary diagnosis requires detailed assessment of symptoms by the clinician. Another explanation for declared overuse of alcohol in this group might be due to competition between youngsters and the interest of 'adult' behavior, which are proven factors related to alcohol use among children and adolescents [11]. It can also be assumed that in this specific study group of graduation adolescents, alcohol use can be seen as a method of self-healing to regulate the level of stress. Studies revealed that many factors, including biological, psychosocial, environmental (e.g. advertisements), as well as those related to personality traits and life-style, may influence child and adolescent alcohol use [15]. It seems that further research exploring factors related to alcohol abuse among the specific group of graduation class students is vital. Such exploration contributes to intervention planning. It should also be noted that 'alcohol abuse' is no longer separately mentioned in the DSM-V criteria. However, our study managed to point out an important problem demanding special attention, as it is emphasized that alcohol use itself among children and adolescents is an increasingly alarming problem globally [11, 15].

The observed higher prevalence of depressive and anxiety disorders among adolescent women is in accord with the general tendency of the more frequent occurrence of mental disorders in women $[2,3,13,14]$. It seems that more targeted and individualized psycho-educational intervention could be undertaken for adolescent women and men.

In the current study, we attempted to show the importance of diagnosing mental disorders in late adolescence, in which the major stress trigger - the graduation exam - is linked to many stress factors [13]. The exam is called 'an exam of adulthood', and it is taken very seriously in Poland, as it is perceived as one of the decisive factors of a youngsters' future. Approaching adulthood, a teenager faces many difficult tasks, and some of these can be overwhelming. In general, youth itself is considered a risk factor for mental problems [6, 8]. Additionally, studies revealed that the treatment rate among adolescents and young adults with mental health problems is especially low. It is estimated that $18-56 \%$ of young people with mental disorders receive specialist care. Moreover, this rate decreases along with the transition into adulthood. Thus, routine screening for mental disorder in these populations is highly recommended $[6,8]$. It is emphasized that a teacher, psychologist, a school counselor or a primary care physician can undertake a screening assessment to identify the first signs or symptoms of mental health problems. Adequate reaction to the specific needs of the adolescents and tailored interventions are proven to be effective both in treatment of mental disorders and in suicide prevention $[3,6]$.

\section{Limitations of the study}

The limitations of the current study include the lack of randomization of participating schools. Due to the lack of medical data, preliminary diagnosis of somatization was impossible. The method used was created according to DSM-IV criteria, hence the prevalence of a preliminary diagnosis of alcohol abuse should be treated with caution. The possible bias of the current study may be related to the fact that we involved the sample of graduation class students which prevent from data generalization on the general population of adolescents. This fact should be taken into account when comparing our observations with the results of other studies.

\section{Conclusions}

1. Alcohol abuse was the most common disorder in the studied adolescent group. This problem is especially frequent among men.

2. Psycho-educative intervention is of great importance among youngsters, especially among graduation adolescents.

3. Screening for mental disorders among graduation adolescents seems vital.

Source of funding: This work was funded by the authors' own resources.

Conflict of interest: The authors declare no conflict of interests.

\section{References}

1. Biechowska E, Wojtyniak B, Moskalewicz B. Zaburzenia psychiczne i zaburzenia zachowania. In: Wojtyniak B, Goryński P, eds. Sytuacja zdrowotna ludności Polski i jej uwarunkowania. Warsaw: National Institute of Public Heath - National Institute of Hygiene; 2016: 184-198 (in Polish).

2. Kiejna A, Piotrowski P, Adamowski T, et al. Rozpowszechnienie wybranych zaburzeń psychicznych w populacji dorosłych Polaków z odniesieniem do płci i struktury wieku - badanie EZOP Polska. Psychiatr Pol 2015; 49(1): 15-27 (in Polish).

3. Wasserman D. Review of health and risk-behaviours, mental health problems and suicidal behaviours in young Europeans on the basis of the results from the EU-funded Saving and Empowering Young Lives in Europe (SEYLE) study. Psychiatr Pol 2016; 50(6): $1093-1107$.

4. Zamachy samobójcze [cited 11.05.2018]. Available from URL: www.statystyka.policja.pl (in Polish).

5. World Health Organization. Preventing suicide: a global imperative. Geneva: WHO; 2014.

6. Richardson LP, McCarrty CA, Radovic A, et al. Research in the integration of behavioral health for adolescents and young adults in primary care settings: a systematic review. J Adolesc Health 2017; 60: 261-269.

7. Carrellas NW, Biederman J, Uchida M. How prevalent and morbid are subtreshold manifestations of major depression in adolescents? A literature review. J Affect Dis 2017; 210: 166-173, doi: http://dx.doi.org/10.1016/j.jad.2016.12.037.

8. Reardon T, Harvey K, Baranowska M, et al. What do parents perceive are the barriers and facilitators to accessing psychological treatment for mental health problems in children and adolescents? A systematic review of qualitative and quantitative studies. Eur Child Adolesc Psychiatry 2017; 26(6): 623-647, doi: 10.1007/s00787-016-0930-6.

9. Spitzer RL, Kroenke K, Williams JB. Validation and utility of a self-report version of PRIME-MD: the PHQ primary care study. JAMA 1999; 282: $1734-1744$

10. Tamburrino MB, Lynch DJ, Nagel RW, et al. Primary care evaluation of mental disorders (PRIME-MD) screening for minor depressive disorder in primary care. Prim Care Companion J Clin Psychiatry 2009; 11(6): 339-343, doi: 10.4088/PCC.08.m00711.

11. Resler K, Cichosz D. The abuse of alcohol by children and young people in Poland and in the world. Pediatr Med Rodz 2015; 11(3): 295-301. 
12. Konarzewska B, Kiss B, Popławska R, et al. Wczesna diagnostyka zaburzeń depresyjnych i lękowych w praktykach lekarzy rodzinnych. Fam Med Prim Care Rev 2006; 8(3): 650-651 (in Polish).

13. Dymowska A, Nowicka-Sauer K. Depresja wśród młodzieży - problem wciąż aktualny. Forum Med Rodz 2015; 9(2): $13-15$ (in Polish).

14. Modrzejewska R, Bomba J. Prevalence of mental disorders and psychoactive substance use in metropolitan 17-year old youth population. Psychiatr Pol 2010; 44(4): 579-592.

15. National Institute on Alcohol Abuse and Alcoholism. Alcohol Alert No 37; July 1997 [cited 15.06.2018]. Available from URL: www.niaaa. nih.gov/alcohol-alert.

Tables: 1

Figures: 0

References: 15

Received: 14.05.2018

Reviewed: 15.05.2018

Accepted: 09.07.2018

Address for correspondence:

Katarzyna Nowicka-Sauer, MA, PhD

Zakład Medycyny Rodzinnej GUMed

ul. Dębinki 2

80-211 Gdańsk

Polska

Tel.: +48 58 349-15-75

E-mail: kpsauer@gumed.edu.pl 